For arbitrary bed and edge geometries, solutions are obtained by means of the method of characteristics, which reduces the problem to solving simultaneously three ordinary first-order differential equations. The integration, which is performed by numerical methods, is generally begun at the edge, where the necessary boundary conditions are known.

The method has been applied to model the elevation contours and the flow pattern of the Greenland ice sheet, using the bottom topography revealed by radio echo-soundings and the present edge geometry. The result is in surprisingly good agreement with our knowledge of the ice-sheet topography and flow pattern, all significant ice divides and ice streams being reproduced. This result suggests, that the method can be applied to model the shape and flow pattern of ice sheets under glacial conditions, using information about former ice-edge positions. This has been attempted for north-west Greenland and Queen Elizabeth Islands, with various ice-margin positions. The topography and flow pattern of the reconstructed iceage ice sheets is discussed in the light of uplift data, and long $\delta^{18} \mathrm{O}$-records obtained from Greenland and north Canadian ice cores.

\title{
THEORY OF DEFORMATIONS WITHIN IGE SHEETS DUE TO BOTTOM UNDULATIONS
}

\author{
By Sigfus J. Johnsen, KJeld Rasmussen, * and Niels Reeh \\ (Geophysical Isotope Laboratory, University of Copenhagen, Haraldsgade 6, DK-2200 \\ Copenhagen N, Denmark)
}

Abstract. Bedrock undulations of glaciers and ice sheets cause undulations of the ice surface and of internal layers. Models are constructed, that describe this phenomenon, using perturbation techniques and utilizing the stress function as harmonic solution to the full biharmonic equation. This approach is an extension of a previous treatment of the problem, which was based on the solution of the Laplace equation. This solution is shown to be inadequate. Two types of ice flow, with and without bottom sliding, are considered. Furthermore, in order to cope with the variation of viscosity with depth, semi-analytical multi-layer models have been constructed.

For the models considered, transfer functions, relating amplitudes of surface and bottom undulations, phase angles, and variation with depth of perturbational stress and velocity components, and in particular of the amplitude of internal isochronic layers, are presented. The predictions of the models presented show significant differences mutually as well as compared with those of previous theories. This opens up the possibility of using field data to check the models and possibly draw conclusions regarding flow conditions at the ice-rock interface and regarding viscosity variations with depth.

\footnotetext{
* Present address: Geographical Institute, University of Copenhagen, Haraldsgade 68, DK-2 I oo Copenhagen, Denmark.
} 